\title{
Ovocidal action of glutaraldehyde and benzalkonium chloride mixture on Aonchotheca bovis (Nematoda, Capillariidae) embryogenesis
}

\author{
V. V. Melnychuk*, I. D. Yuskiv**, M. A. Pishchalenko* \\ *Poltava State Agrarian Academy, Poltava, Ukraine \\ **Stepan Gzhytskyj Lviv National University of Veterinary Medicine and Biotechnologies, Ukraine
}

Article info

Received 12.02.2020

Received in revised form 09.03.2020

Accepted 10.03.2020

Poltava State Agrarian Academy, Skovorody st., 1/3, Poltava, 36003, Ukraine. Tel.: + 38-066-674-78-09.

E-mail:melnychyk86@ukr.net

Stepan Gzhytskyj Lviv National University of Veterinary Medicine and Biotechnologies, Pekarska st., 50,

Lviv, 79000, Ukraine

Tel.: +38-063-223-36-22.

E-mail:igoryuskiv@ukr.net

\begin{abstract}
Melnychuk, V. V., Yuskiv, I. D., \& Pishchalenko, M. A. (2020). Ovocidal action of glutaraldehyde and benzalkonium chloride mixture on Aonchotheca bovis (Nematoda, Capillariidae) embryogenesis. Regulatory Mechanisms in Biosystems, 11(2), 175179. doi:10.15421/022026
\end{abstract}

Deinvasion, aimed at elimination of environmental exogenic stages of invasion agents and avoidance of their invasion to host organism, occupies an important place in the complex of sanitary and prophylactic activities against animal helminthosis diseases. Application of glutaraldehyde and benzalkonium chloride at vital activity and embryogenesis of Aonchotheca bovis (Schnyder, 1906) obtained from nematode female gonads was investigated with different concentration and exposures. Two test-cultures were used in the experiment. The first culture contained non-invasive eggs of $A$. bovis, the second contained invasive ones, obtained by the laboratory culturing of gonadic eggs until mobile larva maturing. It was established that glutaraldehyde and benzalkonium chloride mixture has a deinvasive capacity against $A$. bovis eggs, parasitizing on sheep. Ovocidal efficiency indexes appeared higher with use of the test culture against the non-invasive capillaria eggs' test-culture. So, the high level of ovocidal efficiency of glutaraldehyde and benzalkonium chloride mixture against non-invasive $A$. bovis eggs culture was established at the concentration of $0.5 \%$ and exposure of $10-60 \mathrm{~min}$ (93.6-100.0\%), and against the invasive $A$. bovis egg culture - at the concentration of $0.5 \%$ and exposure of 30 and $60 \mathrm{~min}(90.3-94.6 \%)$ and $1.0 \%$ at all exposures $(100.0 \%)$. Ovocidal activity of the examined mixture was accompanied by specific morphological changes of nematode eggs structure. Destruction of the egg envelope, embryo loosening and decay and its dissolution were observed. Such changes are proved by metric indexes of width and length of capillaria eggs, envelope thickness and cap length, indicating the violation of embryogenesis of $A$. bovis. Thus, glutaraldehyde and benzalkonium chloride mixture of $1.0 \%$ concentration is a promising deinvasive agent suitable for effective fight against and prophylaxis of sheep-breeding nematodosis.

Keywords: capillariasis; sheep; deinvasion; capillaria eggs; viability.

\section{Introduction}

The results of helminthology investigations indicate the wide distribution of sheep helminthosis, which is caused by gastrointestinal nematodes (Wilmsen et al., 2014; Mavrot et al., 2015; Rupa \& Portugaliza, 2016; Hamer et al., 2019). They include such a parasite as Aonchotheca bovis Schnyder, 1906 (syn. Capillaria bovis) - ruminant capillariasis agent, found in the USA, Indonesia, Poland, Turkey, India and Ukraine. According to data, invasion extensity varies from 3.5 to $27.0 \%$ (Worley et al., 1980; Umur, 1996; Beriajaya \& Copeman, 1998; Kowal et al., 2012; Zvegintsova et al., 2015)

Deinvasion, aimed at elimination of environmental exogenic stages of invasion agents and avoidance of their invasion to host organism, occupies an important place in the complex of sanitary and prophylactic activities for animal helminthosis diseases. All of this prevents epidemic outbreaks of invasive diseases, including zooanthroponosis, and restricts the possibility of these pathogens to spread capacity (Tamási, 1995; Mielke \& Hiepe, 1998; Zóltowska et al., 2000).

It must be considered that part of the life cycle of animal helminthosis agents takes place in the external environment, mostly their exogenic development, especially that of geohelminths. Propagative nematode stages (eggs and larvae) exist in the evnironment for a long time, leading to its bio-contamination and to ecological conflict in the case of zoonosis (Dubná et al., 2007; Jiménez, 2007; Traversa et al., 2014; Moskvina et al., 2016). Also worth considering is the fact that eco-climatic and socio-economic changes, population migration, urbanization cause increase in anthropogenic pressure on biocenoses and promote the accumulation of parasite embryos in the environment and their adaptive changes, which increases their viability and resistance against negative environmental factors (Kates, 1965; Calegaro-Marques \& Amato, 2014; Cable et al., 2017; Boyko \& Brygadyrenko, 2019).

Parasite contamination is a kind and a component of bio-contamination, and differs from other contamination types by its selectivity, caused by the very nature of parasitism. Parasite contamination of the environment develops not "by itself", but amid the complex effect of several factors (industrial, domestic, agricultural) and several contamination types (chemical, physical, organic), it is tightly connected with natural preconditions and social factors, determining its geographic position and intensity (Stromberg, 1997; Nowakowicz-Dębek et al., 2001). So, the level of soil contamination of helminth exogenic stages in Kharkiv region (Ukraine) varies from $10.0 \%$ to $55.5 \%$. Moreover, it is proved that livestock and small cattle excrete Strongylata spp. (285 eggs/g) into the environment with their faeces, and cats and dogs Toxocara spp. (75 eggs/g) and Dipylidium caninum (6 eggs/g) (Paliy et al., 2019). Soil contamination in some regions of India was $12.84 \%$ and reached $17.64 \%$ dependent on soil type (Sudhakar et al., 2013). On pig farms of Sweden pasture soil contamination could reach 11,700 eggs $/ \mathrm{kg}$ for Ascaris suum and 220 eggs $/ \mathrm{kg}$ for Trichuris suis. The highest eggs concentrations in the soil were found in the regions with the most frequent pig pasturing (Lindgren et al., 2019). 
Thus, for effective prophylactic and fight against the spreading of animal helminthosis agents, whose exogenic stages develop and gain invasive features in the environment, it is necessary to apply a complex of activities, aimed at the destruction of parasite embryo at the different levels of development in the environment (Boyko \& Brygadyrenko, 2016, 2017). The necessity of deinvasion is also caused by the potential role of parasites as indicators of overall environment contamination (Naidoo et al., 2016; Moazeni et al., 2017).

According to this, the approbation and determination of deinvasive efficiency of modern, ecologically safe and economically accessible disinfective agents against agents of gastrointestinal sheep nemathodosis allows us to make a prophylactic of parasite contamination, minimize the spread of helminthosis, and provide veterinary well-being, which will promote sheep-breeding development.

The purpose of this work was to investigate the effect of different concentrations of glutaraldehyde and benzalkonium chloride mixture at the viability and exogenic development process of the nematode Aonchotheca bovis in laboratory conditions.

\section{Materials and methods}

The research was performed during 2018-2019 at the laboratory of the Parasitology and Veterinary and Sanitary Expertise Department of Poltava State Agrarian Academy. Two egg cultures obtained from gonads of female A. bovis nematodes were used as test-cultures. Nematodes were obtained by the full helminthology dissection of the intestine of dead or slaughtered sheep (Skriabyn, 1928). The species was determined by the key (Skriabyn et al., 1957). The first test-culture contained non-invasive $A$. bovis eggs, the second - invasive eggs, obtained by culturing of gonadal eggs in laboratory conditions. The obtained testculture of capillaria eggs were then rinsed into separate Petri dishes by distilled water.

The disinfective agent examined contained the mixture of active compounds: glutaraldehyde $\left(\mathrm{C}_{5} \mathrm{H}_{8} \mathrm{O}_{2}\right)-25.0 \mathrm{~g}$, benzalkonium chloride $\left(\mathrm{C}_{6} \mathrm{H}_{5} \mathrm{CH}_{2} \mathrm{~N}\left(\mathrm{CH}_{3}\right)_{2} \mathrm{RCl}\right)-12.5 \mathrm{~g}$. To investigate its ovocidal activity against $A$. bovis eggs different concentrations were prepared $(0.25 \%$, $0.5 \%, 1.0 \%)$, which were tested with different exposures $(10,30,60 \mathrm{~min})$. To the test-cultures, prepared with invasive and non-invasive eggs, the equal volumes of agent with particular concentration were added. After appropriate exposition the test-cultures were rinsed by distillate 4 times. Two A. bovis test-cultures (invasive and non-invasive) were prepared separately, without exposure to the investigated agent. The experimental and control test-culture in Petri dishes were placed into the thermostat at $27^{\circ} \mathrm{C}$ with periodic aeration. Test-cultures with invasive eggs were observed during 3 days and with non-invasive - during 27 days. Embryogenesis of non-invasive $A$. bovis eggs was separately noted for experimental and control test-cultures. Developmental level of eggs and presence of various deformations in capillaria eggs' morphological structures were noted, and their metric parameters during development till the invasive stage were recorded.

Ovocidal efficiency (OE, \%) of different concentrations was determined by the formula (Volkov \& Simonov, 1977):

$$
O E=100-\left(Y_{1} / Y_{2}\right) \times 100
$$

where $Y_{1}-$ number of live eggs in experimental test-culture, $Y_{2}-$ number of live eggs in control test-culture.

Ovocidal efficiency evaluation was performed by the following indexes: high level efficiency $-90-100 \%$, satisfactory $-60-90 \%$, nonsatisfactory - up to $60 \%$ (Yevstafieva \& Natjagla, 2017).

Morphometric parameters of $A$. bovis eggs (egg length and width, cup length and width) were examined during their cultivation using ImageJ soft for Windows ${ }^{\mathbb{B}}$ (version 2.00) in interactive mode with ${ }^{\times} 10$, ${ }^{\times} 40,{ }^{\times} 100$ objectives and ${ }^{\times} 10$ photo-ocular. Microphotography was performed using digital microscope camera MikroMed 5 Mpix (China).

Statistical processing of the experimental results was carried out using Statistica 10 (StatSoft Inc., USA) software. Standard deviation (SD) and average values (x) were calculated. Significance of difference between average values in the studied groups of nematodes was established using one-way analysis of variance and F-test (with consideration of Bonferroni's correction) for $95 \%$ confidence level.

\section{Results}

It was established by results that glutaraldehyde and benzalkonium chloride mixture has deinvasive capacity concerning $A$. bovis eggs parasitizing on sheep. However, indexes of efficiency were different depending on mixture concentration and test culture type. Using testculture with invasive capillaria eggs, the high level of ovocidal efficiency was established at $0.5 \%$ dilution with 30 and $60 \mathrm{~min}$ exposure $(\mathrm{OE}-$ 90.3-94.6\%), and at 1.0\% dilution for all exposures (OE - 100.0\%, Table 1).

Table 1

Ovocidal activity of glutaraldehyde and benzalkonium chloride mixture on test-culture of invasive Aonchotheca bovis eggs ( $\mathrm{n}=100, \%)$

\begin{tabular}{|c|c|c|c|c|c|}
\hline \multirow{2}{*}{$\begin{array}{c}\text { Exposure, } \\
\text { min }\end{array}$} & \multirow{2}{*}{ Indexes } & \multicolumn{3}{|c|}{ Concentration } & \multirow{2}{*}{ Control } \\
\hline & & $0.25 \%$ & $0.5 \%$ & $1.0 \%$ & \\
\hline \multirow{3}{*}{10} & Mobile larva in egg & 30.0 & 13.0 & - & 93.0 \\
\hline & Egg death & 70.0 & 87.0 & 100.0 & 7.0 \\
\hline & $\mathrm{OE}$ & 67.7 & 86.0 & 100.0 & - \\
\hline \multirow{3}{*}{30} & Mobile larva in egg & 23.0 & 9.0 & - & 93.0 \\
\hline & Egg death & 77.0 & 91.0 & 100.0 & 7.0 \\
\hline & $\mathrm{OE}$ & 75.2 & 90.3 & 100.0 & - \\
\hline \multirow{3}{*}{60} & Mobile larva in egg & 18.0 & 5.0 & - & 93.0 \\
\hline & Egg death & 82.0 & 95.0 & 100.0 & 7.0 \\
\hline & $\mathrm{OE}$ & 80.6 & 94.6 & 100.0 & - \\
\hline
\end{tabular}

A satisfactory level of ovocidal activity was established while using the investigated mixture at concentration $0.25 \%$ with exposure of 10 to $60 \mathrm{~min}(\mathrm{OE}-67.7-80.6 \%)$, and $0.5 \%$ with exposure of $10 \mathrm{~min}(\mathrm{OE}-$ $86.0 \%$ ). Viability of control culture of invasive $A$. bovis eggs was $93.0 \%$ (only $7.0 \%$ of eggs had died during the experiment).

Ovocidal activity of investigated mixture on invasive capillaria eggs was characterized by their morphological changes, appeared as larvae mobility loss, by their induration with gradual loosening and dissolution (Fig. 1a). Destruction of the egg envelope and decay of eggs into separate fragments were also noted (Fig. 1b).

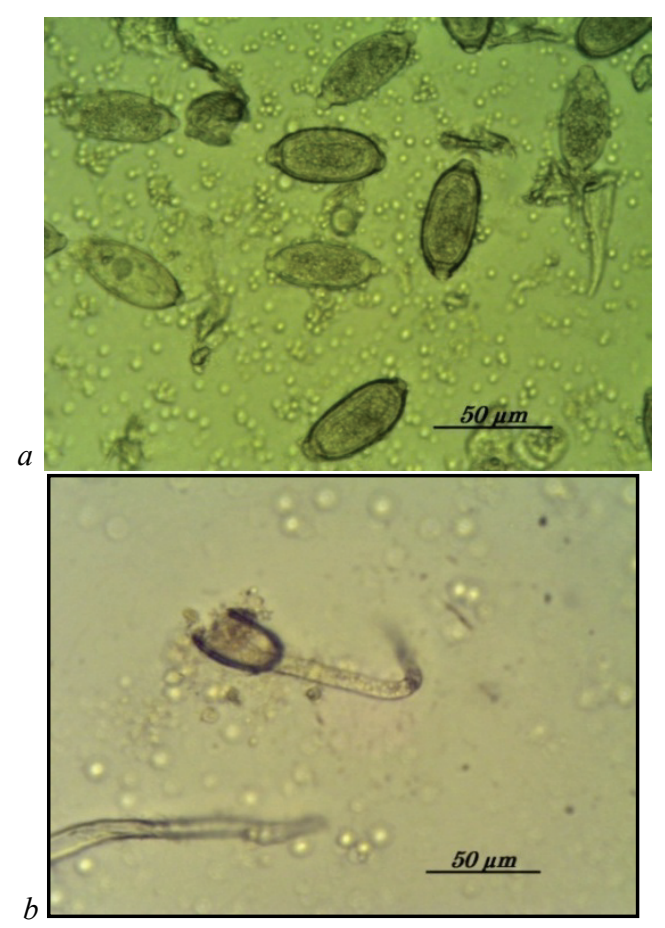

Fig. 1. Morphological changes of Aonchotheca bovis invasive eggs in test-culture, treated with glutaraldehyde and benzalkonium chloride mixture: $a$-induration, loosening and larvae dissolution,

$b$ - eggs envelope destruction, exit and destruction of larva

Using test-culture with non-invasive capillaria eggs, ovocidal activity of glutaraldehyde and benzalkonium chloride mixture appeared higher compared to invasive $A$. bovis eggs (Table 2). 
Table 2

Ovocidal activity of glutaraldehyde and benzalkonium chloride mixture on test-culture of non-invasive Aonchotheca bovis eggs during their embryogenesis $(\mathrm{n}=100, \%)$

\begin{tabular}{clcccc}
\hline \multirow{2}{*}{$\begin{array}{c}\text { Exposure, } \\
\text { min }\end{array}$} & Indexes & \multicolumn{3}{c}{ Concentration } & \multirow{2}{*}{ Control } \\
\cline { 3 - 5 } 10 & & $0.25 \%$ & $0.5 \%$ & $1.0 \%$ & \\
\multirow{2}{*}{10} & Mobile larva in egg & 20.0 & 5.0 & - & 79.0 \\
& Egg death & 80.0 & 95.0 & 100.0 & 21.0 \\
\multirow{4}{*}{30} & OE & 74.6 & 93.6 & 100.0 & - \\
& Mobile larva in egg & 17.0 & 2.0 & - & 79.0 \\
& Egg death & 83.0 & 98.0 & 100.0 & 21.0 \\
\multirow{2}{*}{60} & OE & 78.4 & 97.4 & 100.0 & - \\
& Mobile larva in egg & 11.0 & - & - & 79.0 \\
& Egg death & 89.0 & 100.0 & 100.0 & 21.0 \\
& OE & 86.0 & 100.0 & 100.00 & - \\
\hline
\end{tabular}

High ovocidal activity level of mixture was established at concentrations $0.5 \%$ and $1.0 \%$ with exposure of $10-60 \mathrm{~min}(\mathrm{OE}-93.6$ $100.0 \%)$. Satisfactory ovocidal activity level was established with the mixture using $0.25 \%$ concentration and $10-60$ min exposure $(\mathrm{OE}-$ 74.6-86.0\%). Control culture had the $A$. bovis invasive eggs viability of $79.0 \%$ ( $21.0 \%$ of eggs had died during embryogenesis).

Deinvasive activity of investigated mixture on non-invasive capillaria eggs caused certain morphological changes during their embryogenesis. The highest number of dead eggs was counted at the 10-14 days of the experiment, by the time of bean-shaped embryo formation. Disin- fectant reactants' penetration into the egg led to the breaking of its envelope (Fig. 2a), embryo loosening and decay (Fig. 2b) and its dissolution inside the egg (Fig. 2c).

Simultaneously, studying the ovocidal activity of glutaraldehyde and benzalkonium chloride mixture on test-culture of non-invasive A. bovis eggs and its maturing capacity during embryogenesis, metrical changes were recorded for eggs parameters. Experimental test-culture had significantly lower eggs length parameters, compared to those of the control test-culture, which had $79.0 \%$ invasive eggs formed by the 27th day of cultivating. The differences were as follows: using $0.5 \%$ concentration $-2.42 \%(58.91 \pm 0.99 \mu \mathrm{m}, \mathrm{P}<0.05), 1.0 \%$ concentration $3.81 \%$ (58.07 $\pm 1.42 \mu \mathrm{m}, \mathrm{P}<0.01$, Fig. 3a). Also egg width was higher in the experimental test-culture. Moreover, the higher the mixture (to treat experimental $A$. bovis eggs test-culture) concentration was, the less their width appeared: with $0.5 \%$ - by $5.94 \%(25.27 \pm 1.08 \mu \mathrm{m}, \mathrm{P}<$ $0.05), 1.0 \%-9.59 \%(26.29 \pm 1.49 \mu \mathrm{m}, \mathrm{P}<0.01$, Fig. 3b). Changes of eggs' cap length and envelope thickness were noticed too. At day 27 of cultivation length of capillaria eggs was higher in the experimental culture: with $0.5 \%$ - by $9.67 \%(2.69 \pm 0.20 \mu \mathrm{m}, \mathrm{P}<0.05)$, with $1.0 \%-$ by $19.54 \%(3.02 \pm 0.19 \mu \mathrm{m}, \mathrm{P}<0.001$, Fig. $3 \mathrm{c})$. Thickness of the eggs' envelope appeared higher in the experimental test-culture too: with $0.5 \%$ - by $6.78 \%(2.36 \pm 0.11 \mu \mathrm{m}, \mathrm{P}<0.05)$, with $1.0 \%-17.60 \%(2.67 \pm$ $0.22 \mu \mathrm{m}, \mathrm{P}<0.001$, Fig. 3e). Egg cap width didn't differ significantly between experimental and control test-cultures, their size varied from $7.01 \pm 0.39$ to $7.18 \pm 0.26 \mu \mathrm{m}$ (Fig. $3 \mathrm{~d}$ ).
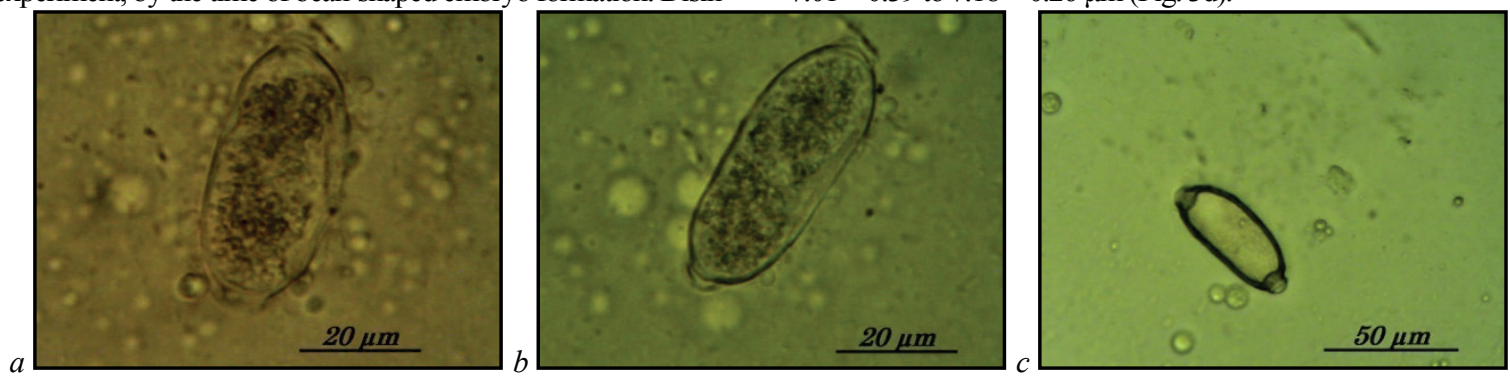

Fig. 2. Morphological changes of non-invasive Aonchotheca bovis eggs in test-culture, treated with glutaraldehyde and benzalkonium chloride mixture: $a$-envelope destruction, $b$-embryo loosening and decay, $c$ - embryo dissolution
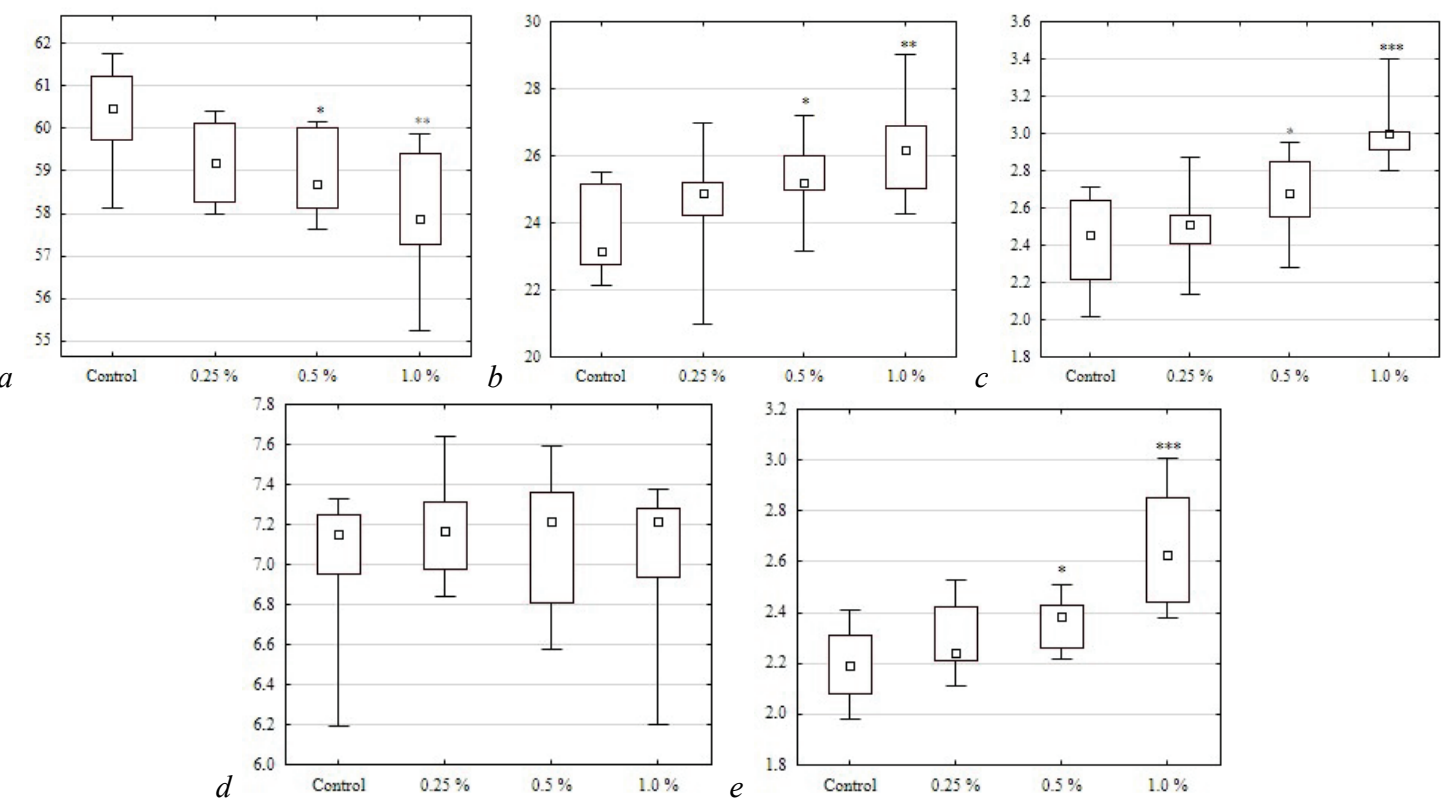

Fig. 3. Metric indexes of Aonchotheca bovis eggs during their embryogenesis, with treatment with a test-culture with glutaraldehyde and benzalkonium chloride mixture in different concentrations and exposure of $60 \mathrm{~min}: a$ - egg length, $b$ - egg width, $c$ - egg cap length, $d$-egg cap width, $e$ - envelope thickness $(\mu \mathrm{m}) ;{ }^{*}-\mathrm{P}<0.05 ; * *-\mathrm{P}<0.01 ; * * *-\mathrm{P}<0.001$ compared to eggs indexes in control test-culture (with Bonferroni correction); the small square in the center corresponds to the median, the lower and upper borders of the large rectangular correspond to the first and the third quartiles, respectively, vertical line segments, directed up and down from the rectangular, correspond to minimum and maximum values $(\mathrm{n}=10)$ 
Such changes, in our opinion, indicate the growth and development termination due to effect of the disinfectant. Moreover, the higher the ovocidal activity of the mixture on the test-culture was, the more notable their metric indexes changes were. While treating the test-culture of non-invasive eggs with $0.25 \%$ concentration mixture, morphometric indexes of eggs length and width, cap length and envelope thickness during embryogenesis did not differ significantly from those of control test-culture eggs. This indicates their further development and weak deinvasive capacity of glutaraldehyde and benzalkonium chloride mixture concerning sheep capillariasis agents.

\section{Discussion}

Deinvasive treatment development is based on the knowledge of parameters of resistance of the agent to natural or artificial physical, chemical and biological factors. It is known that survival of parasitosis agents, particularly nematodosis, depends on intensity of treatment as well as on biological resistance capacity of exogenic stages of parasites, which is related with their eggs envelope structure. Different agents relate to different treatment in different ways (Wharton, 1983; Smales, 1984). Literature data states that Ascaridata, Trichurata and Strongylata eggs are the most resistant to adverse environmental factors. This is due to their common egg structure, confirmed by electronic microscopy. External and medial envelopes of Ascaridata eggs protect from mechanical threat to the embryo, and the internal one (lipid) - from chemical (Lýsek et al., 1985; Brownell \& Nelson, 2006). Trichurata eggs have a multilayer envelope, which has the external layer - bright, thin and noticeable only near the poles, it enwraps the whole egg. The next layer is thick, has a complex structure and possibly colouration. An additional layer is discovered also - transparent or dark, it connects on the poles with plugs. The external layer forms a closed line from the egg's middle. Some envelope layers protect the embryo from mechanical threat, some from chemical (Meng et al., 1986; Mahmoud, 2002).

According to experience, the chemical deinvasive way is the main and the most effective. It involves applying the agents based on different chemical compounds. Nowadays, plenty of sanitization, disinfection and deinvasive agents for zoological and veterinary aims are known. They are different by efficiency, toxicity and price (Morrondo et al., 2006; Zhu et al., 2013; Oliveira et al., 2014).

We studied deinvasive features of glutaraldehyde and benzalkonium chloride mixture on test-cultures of invasive and non invasive A. bovis eggs, parasites of sheep. It was proved that ovocidal efficiency indexes depends on capillaria test-culture type. The invasive eggs' culture appeared the most resistant to treatment by the investigated mixture, non-invasive - the least. Efficiency indexes depended on disinfectant concentration and exposure. High ovocidal efficiency level for invasive test-culture was registered with $0.5 \%$ concentration and 30 and $60 \mathrm{~min}$ exposure (up to $94.6 \%$ ), and with $1.0 \%$ and $10-60 \mathrm{~min}$ $(100.0 \%)$. Concerning non-invasive culture, a high level was registered with $1.0 \%$ concentration and $10-60 \mathrm{~min}$ exposure (up to $100.0 \%$ ).

We demonstrated earlier the deinvasive features of chlorine-contained disinfectants regarding non-invasive culture of $A$. bovis eggs, obtained from sheep. The most effective were concentrations of 1.0, 1.5 and $2.0 \%$ at exposure of 10-60 min, for which ovocidal efficiency varied 91.1-100.0\% (Melnychuk \& Yuskiv, 2018). Also the larvocidal features of disinfectants, containing glutaraldehyde, were studied. Death of $100 \%$ of $\mathrm{L}_{3} H$. contortus after 24 hour exposure was observed with use of $1 \%$ solution of mixture of alkylbenzyldimethylammonium chloride and didecyldimethylammonium chloride, and also 5\% - glutaraldehyde, formaldehyde and alkylbenzyldimethylammonium chloride (Zazharskyi et al., 2018).

It was suggested that eggs of nematodes of genus Ascaris be used as the resistance standard for determining the disinfective features of different agents. That's why harmful activity of such agents on the viability on ascarid eggs possibly indicates their ovocidal efficiency for the exogenic stages of other nematodes species also (Pecson et al., 2006; Nordin et al., 2009; Maya et al., 2010). Also the major advantage in using $A$. suum eggs as a resistance standard is the ease of obtaining them and preparing them in test-culture. Matured helminths are ob- tained from a pig's small intestine at slaughter (Orta de Velasquez et al., 2004). It should be considered that $A$. suum eggs, obtained from experimentally infected pig faeces, are more resistant to chemical compounds due to egg envelope tightening after its exit from the nematode female uterus (Butkus et al., 2011; Daugschies et al., 2013). Some authors experimented on the deinvasive efficiency on strongylids, $\mathrm{L}_{1}$ of which hatch fast, and this allowed rapid evaluation of the harmful features of the investigated agents. However, this analysis is not perfect for disinfectants' screening, because strongylid eggs, with rare exceptions, are not so resistant in the environment and, thus, are not the main target for practical deinvasion (Matthews et al., 2012). Thus, use of exogenic stages of development of a particular species agent, obtained from animals under particular conditions, as the test-object allows proper and effective selection of disinfective agents and modes of their application. It increases the efficiency of measures for struggle and prophylaxis against parasitic diseases.

That's why we performed investigations concerning ovocidal activity of glutaraldehyde and benzalkonium chloride mixture in different concentrations on $A$. bovis eggs embryogenesis, where $79.0 \%$ of invasive eggs were forming in the control non-treated test culture by the 27th day of cultivation. It is worth noting that maturation of capillaria eggs was followed by their metric changes. Morphological and metric changes in eggs were noted in experimental test-cultures, treated by the glutaraldehyde and benzalkonium chloride mixture. At the same time, the greater the ovocidal efficiency of the mixture was, the more significant were the metric changes in width and length of capillaria eggs, as well as envelope thickness and cap length.

The investigations performed allow us to recommend the glutaraldehyde and benzalkonium chloride mixture in $1.0 \%$ concentration and $10-60 \mathrm{~min}$ exposure as an effective deinvasive agent to be used in the fight and prophylaxis against sheep capillariasis in farming under different types of ownership.

\section{Conclusion}

The results obtained indicate expressed deinvasive features of disinfective glutaraldehyde and benzalkonium chloride mixture on the nematode Aonchotheca bovis eggs, parasitizing on sheep. The highest ovocidal efficiency level (up to $100.0 \%$ ) was established for $1.0 \%$ concentration and 10-60 min exposure. Harmful effect was characterized by specific changes of eggs morphological structure such as envelope breaking, larvae exit and death, embryo dissolution. The level of efficiency depended on the type of treated test-culture. Invasive $A$. bovis eggs appeared more resistant to disinfectant action than non-invasive. Data obtained on ovocidal efficiency is proved by metric indexes of non-invasive eggs during cultivation also. Under treatment by glutaraldehyde and benzalkonium chloride mixture, length and width of eggs cap and envelope thickness changed. Egg length was less (by 1.9 $3.8 \%$ ), and width, cap length and egg envelope were larger (respectively by $5.9-9.5 \%, 9.6-19.5 \%$ and $6.7-17.6 \%$ ) compared to capillaria eggs indexes of the non-treated test-culture.

\section{References}

Beriajaya, \& Copeman, D. B. (1998). An estimate of seasonality and intensity of infection with gastrointestinal nematodes in sheep and goats in West Java. Jurnal Ilmu Ternak dan Veteriner, 2(4), 270-276.

Boyko, A. A., \& Brygadyrenko, V. V. (2016). Influence of water infusion of medicinal plants on larvae of Strongyloides papillosus (Nematoda, Strongyloididae). Visnyk of Dnipropetrovsk University, Biology, Ecology, 24(2), 519-525.

Boyko, A. A., \& Brygadyrenko, V. V. (2017). Changes in the viability of the eggs of Ascaris suum under the influence of flavourings and source materials approved for use in and on foods. Biosystems Diversity, 25(2), 162-166.

Boyko, O. O., \& Brygadyrenko, V. V. (2019). The impact of acids approved for use in foods on the vitality of Haemonchus contortus and Strongyloides papillosus (Nematoda) larvae. Helminthologia, 56(3), 202-210.

Brownell, S. A., \& Nelson, K. L. (2006). Inactivation of single-celled Ascaris suum eggs by low-pressure UV radiation. Applied and Environmental Microbiology, 72(3), 2178-2184. 
Butkus, M. A., Hughes, K. T., Bowman, D. D., Liotta, J. L., Jenkins, M. B., \& Labare, M. P. (2011). Inactivation of Ascaris suum by short-chain fatty acids. Applied and Environmental Microbiology, 77, 363-366.

Cable, J., Barber, I., Boag, B., Ellison, A. R., Morgan, E. R., Murray, K., Pascoe, E. L., Sait, S. M., Wilson, A. J., \& Booth, M. (2017). Global change, parasite transmission and disease control: Lessons from ecology. Philosophical Transactions of the Royal Society of London, Series B, Biological Sciences, 372(1719), 20160088.

Calegaro-Marques, C., \& Amato, S. B. (2014). Urbanization breaks up host-parasite interactions: A case study on parasite community ecology of rufous-bellied thrushes (Turdus rufiventris) along a rural-urban gradient. PLoS One, 9(7), e103144.

Daugschies, A., Bangoura, B., \& Lendner, M. (2013). Inactivation of exogenous endoparasite stages by chemical disinfectants: Current state and perspectives. Parasitology Research, 112(3), 917-932.

Dubná, S., Langrová, I., Jankovská, I., Vadlejcha, J., Pekárb, S., Nápravníka, J., \& Fechtner, J. (2007). Contamination of soil with Toxocara eggs in urban (Prague) and rural areas in the Czech Republic. Veterinary Parasitology, 144(1-2), 81-86.

Hamer, K., McIntyre, J., Morrison, A. A., Jennings, A., Kelly, R. F., Leeson, S., Bartley, D. J., Chaudhry, U., Busin, V., \& Sargison, N. (2019). The dynamics of ovine gastrointestinal nematode infections within ewe and lamb cohorts on three Scottish sheep farms. Preventive Veterinary Medicine, 171, 104752

Jiménez, B. (2007). Helminth ova control in sludge: a review. Water Science and Technology, 56(9), 147-155.

Kates, K. C. (1965). Ecological aspects of helminth transmission in domesticated animals. American Zoologist, 5, 95-130.

Kowal, J., Nosal, P., Bonczar, Z., \& Wajdzik, M. (2012). Parasites of captive fallow deer (Dama dama L.) from southern Poland with special emphasis on Ashworthius sidemi. Annals of Parasitology, 58(1), 23-26.

Lindgren, K., Gunnarsson, S., Höglund, J., Lindahl, C., \& Roepstorff, A. (2019). Nematode parasite eggs in pasture soils and pigs on organic farms in Sweden. Organic Agriculture, 2019, in print.

Lýsek, H., Malínský, J., \& Janisch, R. (1985). Ultrastructure of eggs of Ascaris lumbricoides Linnaeus, 1758. I. Egg-shells. Folia Parasitologica, 32(4), 381-384.

Mahmoud, L. H. (2002). Scanning electron microscopy of Trichuris trichura. Journal of the Egyptian Society of Parasitology, 32(2), 469-474.

Matthews, J. B., McArthur, C., Robinson, A., \& Jackson, F. (2012). The in vitro diagnosis of anthelmintic resistance in cyathostomins. Veterinary Parasitology, $185,25-31$.

Mavrot, F., Hertzberg, H., \& Torgerson, P. (2015). Effect of gastro-intestinal nematode infection on sheep performance: A systematic review and metaanalysis. Parasites and Vectors, 8(1), 557.

Maya, C., Ortiz, M., \& Jimenez, B. (2010). Viability of Ascaris and other helminth genera non larval eggs in different conditions of temperature, lime $(\mathrm{pH})$ and humidity. Water Science and Technology, 62, 2616-2624.

Melnychuk, V., \& Yuskiv, I. (2018). Disinvasive efficacy of chlorine-based preparations of domestic production for eggs of nematodes of the species Aonchotheca bovis parasitizing in sheep. Ukrainian Journal of Veterinary and Agricultural Sciences, 1(2), 15-18.

Meng, X. Q., Wang, S. S., Zhou, W. Q., Wang, B. X., Han, W. S., \& Wang, L. (1986). The operculum-plug area and membranous structure of the eggs of Trichuris trichiura. Scanning Electron Microscopy, 3, 1015-1018.

Mielke, D., \& Hiepe, T. (1998). The effectiveness of different disinfectants based on p-chloro-m-cresol against Ascaris suum eggs under laboratory conditions. Berliner und Münchener Tierärztliche Wochenschrift, 111(7-8), 291-294.

Moazeni, M., Saadaty Ardakani, Z. S., Saharkhiz, M. J., Jalaei, J., Khademolhoseini, A. A., Shams Esfand Abad, S., \& Mootabi Alavi, A. (2017). In vitro ovicidal activity of Peganum harmala seeds extract on the eggs of Fasciola hepatica. Journal of Parasitic Diseases, 41(2), 467-472.

Morrondo, P., Díez-Morrondo, C., Pedreira, J., Díez-Baños, N., Sánchez-Andrade, R., Paz-Silva, A., \& Díez-Baños, P. (2006). Toxocara canis larvae viability after disinfectant-exposition. Parasitology Research, 99(5), 558-561.

Moskvina, T. V., Bartkova, A. D., \& Ermolenko, A. V. (2016). Geohelminths eggs contamination of sandpits in Vladivostok, Russia. Asian Pacific Journal of Tropical Medicine, 9(12), 1215-1217.

Naidoo, D., Archer, C., Louton, B., \& Rodda, N. (2016). Testing household disinfectants for the inactivation of helminth eggs on surfaces and in spills during pit latrine emptying. Water SA, 42(4), 560-570.

Nordin, A., Nyberg, K., \& Vinneras, B. (2009). Inactivation of Ascaris eggs in source-separated urine and feces by ammonia at ambient temperatures. Applied and Environmental Microbiology, 75, 662-667.

Nowakowicz-Dębek, B., Ondrašovič, M., Bis-Wencel, H., \& Saba, L. (2001). Soil pollution with parasite eggs and larvae at fur-bearing animal farms. Medycyna Weterynaryjna, 57(3), 202-203.
Oliveira, G. L., Vieira, T. M., Nunes, V. F., Ruas, M. O., Duarte, E. R., Moreira, D. L., Kaplan, M. A. C., \& Martins, E. R. (2014). Chemical composition and effcacy in the egg-hatching inhibition of essential oil of Piper aduncum against Haemonchus contortus from sheep. Revista Brasileira de Farmacognosia, 24(3), 288-292

Orta de Velasquez, M. T., Martinez, J. L., Monjeramirez, I., \& Rojas-Valencia, M. N. (2004). Destruction of helminth (Ascaris suum) eggs by ozone. Ozone: Science and Engineering, 26, 359-366.

Paliy, A., Sumakova, N., Petrov, R., Shkromada, O., Ulko, L., \& Palii, A. (2019). Contamination of urbanized territories with eggs of helmiths of animals. Biosystems Diversity, 27(2), 118-124.

Pecson, B. M., Barrios, J. A., Johnson, D. R., \& Nelson, K. L. (2006). A real-time PCR method for quantifying viable Ascaris eggs using the first internally transcribed spacer region of ribosomal DNA. Applied and Environmental Microbiology, 72, 7864-7872.

Rupa, A. P. M., \& Portugaliza, H. P. (2016). Prevalence and risk factors associated with gastrointestinal nematode infection in goats raised in Baybay city, Leyte, Philippines. Veterinary World, 9(7), 728-734.

Skrjabin, K. I. (1928). Metod polnyh gel'mintologicheskih vskrytij pozvonochnyh, vkljuchaja cheloveka [The method of complete helminthological autopsy of vertebrates, including humans]. Moscow State University, Moscow (in Russian).

Skrjabin, K. I., Shikhobalova, N. P., \& Orlov, I. V. (1957). Osnovy nematodologii. Trihocefalidy i kapilljariidy zhivotnyh i cheloveka i vyzyvaemye imi zabolevanija [Trichocephalids and capillariids of animals and man and the diseases caused by them. The essentials of nematodology]. Russian Academy of Sciences, Moscow (in Russian).

Smales, L. R. (1984). The egg-shell of Labiostrongylus eugenii (Nematoda, Strongyloidea): Structure and function. International Journal for Parasitology, 14(3), 231-239.

Stromberg, B. E. (1997). Environmental factors influencing transmission. Veterinary Parasitology, 72(3-4), 247-256.

Sudhakar, N. R., Samanta, S., Sahu, S., Raina, O. K., Gupta, S. C., Madhu, D. N., \& Kumar, A. (2013). Prevalence of Toxocara species eggs in soil samples of public health importance in and around Bareilly, Uttar Pradesh, India. Veterinary World, 6(2), 87-90.

Tamási, G. (1995). Testing disinfectants for efficacy. Revue Scientifique et Technique, 14(1), 75-79.

Traversa, D., Frangipane di Regalbono, A., Di Cesare, A., La Torre, F., Drake, J., \& Pietrobelli, M. (2014). Environmental contamination by canine geohelminths. Parasites and Vectors, 7, 67

Umur, S. (1996). Gastro-intestinal nematodes and seasonal activities in sheep in the Kars district. Turkish Journal of Veterinary and Animal Sciences, 21(1), 57-65.

Volkov, F. A., \& Simonov, A. P. (1977). Metod opredelenija ovocidnoj i larvocidnoj jeffektivnosti razlichnyh sredstv [Method for ovocidal and larvocidal efficiency determination of different agents]. Bulletin of the All-Union Order of the Red Banner of Labor K. I. Scriabin Institute of Helminthology, 19, 4750 (in Russian).

Wharton, D. A. (1983). The production and functional morphology of helminth egg-shells. Parasitology, 86(4), 85-97.

Wilmsen, M. O., Silva, B. F., Bassetto, C. C., \& Amarante, A. F. T. (2014). Gastrointestinal nematode infections in sheep raised in Botucatu, state of São Paulo, Brazil. Brazilian Journal of Veterinary Parasitology, 23(3), 348-354.

Worley, D. E., Barrett, R. E., \& Knapp, S. E. (1980). Hosts and distribution of Capillaria bovis (Schnyder, 1906) in domestic and wild ruminants in Northwestern United States. Journal of Parasitology, 66(4), 695-696.

Yevstafieva, V. O., \& Natiagla, I. V. (2017). Vyvchennja dezinvazijnyh vlastyvostej zasobiv dezinfekcii' shhodo jajec' gel'mintiv kurej rodu Capillaria [Study of deinvasive features of disinfection agents regarding chicken parasites eggs of Capillaria genus]. Messenger of Zhytomyr National Agroecology University, 1(1), 128-132 (in Ukrainian).

Zazharskyi, V. V., Davydenko, P., Kulishenko, O., Chumak, V., Kryvaya, A., Biben, I. A., Tishkina, N. M., Borovik, I., Boyko, O. O., \& Brygadyrenko, V. V. (2018). Bactericidal, protistocidal and nematodicidal properties of mixtures of alkyldimethylbenzyl ammonium chloride, didecyldimethyl ammonium chloride, glutaraldehyde and formaldehyde. Regulatory Mechanisms in Biosystems, 9(4), 540-545.

Zhu, L., Dai, J. L., Yang, L., \& Qiu, J. (2013). In vitro ovicidal and larvicidal activity of the essential oil of Artemisia lancea against Haemonchus contortus (Strongylida). Veterinary Parasitology, 195(1-2), 112-117.

Zółtowska, K., Białowas, K., \& Lopieńska, E. (2000). Influence of zinc and lead ions on the development of eggs of Ascaris suum (Nematoda). Wiadomości Parazytologiczne, 46(4), 501-506.

Zvegintsova, N. S., Treus, M. Y., \& Kuzmina, T. A. (2015). Helminths of saiga antelope (Saiga tatarica L.) in the "Askania Nova" Biosphere Reserve, Ukraine. Helminthologia, 52(3), 219-228. 